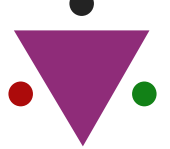

IJCRR

Section: Healthcare

Sci. Journal Impact

Factor: 6.1 (2018)

ICV: 90.90 (2018)

(c) (i) (8)

Copyright@IJCRR

\title{
Quantitative Assessment of Stress Adaptation of Experimental Animals to Field Exposure Based on the Entropy Approach
}

\section{Khudoikulova Shoira Narzullaevna ${ }^{1}$, Laptev Dmitry Sergeevich ${ }^{2}$, Egorkina Svetlana Borisovna ${ }^{3}$, Stepanov Vladimir Alexandrovich ${ }^{3}$, Belykh Vyacheslav Vyacheslavovich²}

'Senior Lecturer of Samarkand State Medical Institute; ${ }^{2}$ Postgraduate Student of lzhevsk State University named after M.T. Kalashnikov; ${ }^{3}$ Doctor of Medical Sciences, Associate Professor of lzhevsk State Medical Academy, Uzbekistan.

\section{ABSTRACT}

Aim and Objective: This article reveals of the work which was devoted to studying the changes in corneal tissues and stress adaptation of laboratory rats with different resistance to the effects of a rotating electric field with 10 and 20 days of exposure. The adaptation of laboratory animals to the effect of a rotating electric field leads to new energy-informational levels in the structure of corneal tissues in the form of subsystems of survival, which are revealed using multifractal parameters.

Method: The limiting adaptability of an animal with a stable psychotype is higher than that of an unstable or ambivalent animal. Estimates of the limits of stress resistance of rats with different psychotype to the influence of an electric field were obtained.

Result: Three mechanisms of adaptation of the structure of corneal tissues under the influence of a field on an animal concerning the sign of the health of the functioning of the organism "norm of chaos" were revealed: - an acute stress state, as in an equilibrium unstable state with increased reproduction of entropy $(\Delta H>0)$, due to additional energy costs for maintaining the equilibrium of the system (informational entropy D1 is higher than the "norm of chaos"); -Adaptation without signs of pathology as in a non-equilibrium steady state $\Delta \mathrm{H}=0$ (informational entropy D1 is close to the "norm of randomness"); - chronic, i.e. stable nonequilibrium state $\Delta \mathrm{H}<0$ (informational entropy D1 is lower than the "norm of chaos").

Key Words: Adaptation, Multifractal ordering, Entropy, Information system, Self-organization, Stress state, Mathematical model

\section{INTRODUCTION}

The work is related to the development of methods and algorithms for recognizing structural changes in tissues in various physiological and pathological conditions on raster images of corneal sections, including for determining the response to stress in keratoconus. ${ }^{1}$ At the present stage, the structures of functional systems have been identified and studied in biomedical research. At the same time, the question of the presence of system-forming factors, based on which the characteristics of the relationships of order, self-organization and chaos are formed, remains open. Traditional methods of studying the adaptive characteristics of animals for several reasons have low accuracy and do not take into account the nature and trend of changes in the state of the body. An approach based on entropy methods of mathematical modelling of information systems of biological objects is promising for integrated assessment of the state of the biosystem, which al- lows us to assess the impact of external factors on changes in entropy indicators and provides a quantitative characteristic of the adaptation process. ${ }^{2}$ Critical indicators of multifractal sets and a universal algorithm for self-organization of adaptation structures are used as indicators of the structure's adaptability to changes in the external factor. ${ }^{2,3}$

The integral regulation of the system based on the principles of cooperation is explained, among other things, by the phenomenon of homeostasis, which provides (with a certain "norm of randomness") a change of control modes. The analysis of synergetic processes is based on the mechanisms of chaotic dynamics of the organism. ${ }^{4}$ To study complex biological systems, we use methods of chaos theory and synergetics which allow us to reveal and analyze the mechanisms of stress adaptation of experimental animals subjected to prolonged exposure to a rotating electric field. ${ }^{5}$ The results of the study of the effect of a rotating electric

\section{Corresponding Author:}

Khudoikulova Shoira Narzullaevna, Senior lecturer of Samarkand State Medical Institute Email: pro.ilmiy@mail.ru

ISSN: 2231-2196 (Print)

Received: 18.07.2020
ISSN: 0975-5241 (Online)

Revised: 09.09.2020
Accepted: 18.10 .2020
Published: 24.11 .2020 
field on the reproductive system of female rats indicate structural changes in the placenta, fetal development delay, and an increase in the frequency of embryonic mortality, which indicates the influence of regulatory systems and compensatory capabilities of the animal on the adaptive capacity of internal organs. ${ }^{6}$

For a quantitative description of the structure of the image of corneal tissues, multifractal (informational) elements are used, which characterize the processes of structural changes that occur under the influence of stress (electric field).

Obtaining estimates of stress adaptation of laboratory animals based on multifractal parameters of the corneal tissue image structure under the influence of an electric field, taking into account the dynamics of information entropy. We aimed for the development of the mathematical model " Information system of corneal tissue structure, to study of the adaptive capacity of corneal tissues of laboratory animals based on the control and controlling parameters of the order of formation of a mathematical model and research of the mathematical model "Information system of the structure of corneal tissues" taking into account the stability of animals.

\section{MATERIALS AND METHODS}

A bitmap image of the fractal objects have limited size $r \times c$ where $r$ is the number of rows, a $c$ - is the number of columns, and the minimum cell is the image pixel, $x_{i j}, i=\overline{1, r}$ and $j=\overline{1, c}$, which characterizes the grayscale from 0 to 255 , where 0 means black and 255 means white. We use a modified method for calculating generalized fractal dimensions which assumes the presence of two types of pixels below:

$$
y_{i j}(\Gamma)=\left\{\begin{array}{ll}
0, & x_{i j} \notin \Gamma \\
1, & x_{i j} \in \Gamma
\end{array}, i=\overline{1, r}, j=\overline{1, c}\right.
$$

where $\Gamma=\left[\gamma_{1}, \gamma_{2}\right]$ - the threshold brightness level, $\Gamma \subset[0,255]$

We will divide the image under study into square cells with side $\delta$, which will vary from 3 to 50 pixels.

The number of single pixels is calculated in each "non-empty" cell:

$$
M_{k}=\sum_{i=r(k)}^{r(k)+\delta-1} \sum_{j=c(k)}^{c(k)+\delta-1} y_{j}(\Gamma), k=\overline{1, N(\delta)}
$$

where $r(k)$ and $c(k)$ are the number of the row and column of the pixel where the $k$-the cell starts, respectively.

Calculating the number of individual pixels in the image:

$$
M=\sum_{k=1}^{N(\delta)} M_{k}
$$

Determining the "population" of the $k$-th cell:

$$
p_{k}=\frac{M_{k}}{M}, k=\overline{1, N(\delta)} .
$$

The normalization condition must be met:

$$
\sum_{k=1}^{N(\delta)} p_{k}=\sum_{k=1}^{N(\delta)} \frac{M_{k}}{M}=1
$$

The moment of the $p_{k}^{q}$-nd order determines the $D_{\mathrm{q}}$ value corresponding to the degree of resolution of the multifractal set:

$$
Z(q, \delta)=\sum_{k=1}^{N(\delta)} p_{k}^{q}
$$

Here $q \in(-\infty, \infty)$. In the literature, the minimum and maximum sparsity are limited to considering $D_{+40}$ and $D_{-40}$.

For integer values $q(-40,-39, \ldots 39,40)$, discrete values $D_{\mathrm{q}, \delta}$ depending on the cell size $\delta$ :

$$
D_{q, \delta}=\left\{\begin{array}{c}
\frac{\ln \sum_{k=1}^{N(\delta)} p_{k}^{q}(\delta)}{(1-q) \ln \delta}, \quad q^{11} \\
\frac{\ln \left(\sum_{k=1}^{N(\delta)} p_{k}(\delta) \times \ln p_{k}(\delta)\right)}{\ln \delta}, \quad q=1
\end{array}\right.
$$

The method of parameterization of structures discussed above is universal and can be used to study disordered structures of any nature. ${ }^{7}$ Adaptation of regulatory systems and compensatory capabilities of an animal with different stress resistance can control the adaptive capacity of internal organs and change the structure of corneal tissues of the animal. Using the "open field" technique at the Department of "Normal physiology" of the Izhevsk state medical Academy, animals were divided into three psychotype: (1) stable, (2) unstable and (3) ambivalent.

Experiments were performed with 10-and 20-day exposures. After exposure to the rotating electromagnetic field, the cornea of the eye was taken and fixed following the requirements of histological studies. Optical images of histological sections of the cornea of experimental animals with different psychotypes of behaviour exposed to a rotating electric field for ten and twenty days were studied at 10x and 20x lens magnification.

Installation of a vortex electric field (Figure 1), consists of a transformer, two pairs of electrodes, a capacitor, and a resistor. The voltage between the electrodes 1 and 2 was used as a reference voltage, relative to the reference voltage, a phase shift voltage $\left(\alpha=45^{\circ}\right)$ was formed with the help of a phaseshifting chain, which was fed to the electrodes 3 and 4 . In the space between the electrodes, the superposition of two 
orthogonal fields, the amplitude values of which were 30.5 $\mathrm{V} / \mathrm{m}$ and $75.9 \mathrm{~V} / \mathrm{m}$, respectively, formed an electromagnetic field that changed according to the sinusoidal law with a frequency of $50 \mathrm{~Hz}$. The power supply of the plant was carried out from the AC network with a voltage of 220V. (Puchkov, 1986).

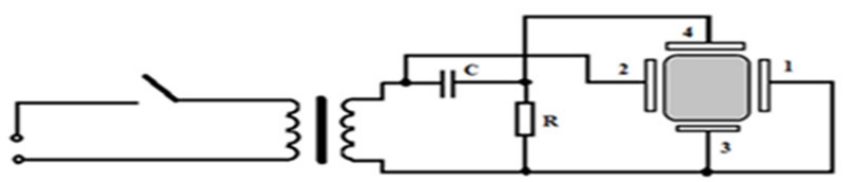

Figure 1: Schematic diagram of an experimental installation.

When developing the mathematical model "information system of corneal tissue structure", the multifractal parameters of the digital image are calculated, the spectra of generalized Reni dimensions (Dq - $\mathrm{q}$ ) and effective structural quantitative characteristics are obtained:

-measure of disorder (hidden periodicity) $\Delta 40=\mathrm{D}_{-40}-\mathrm{D}_{+40}$ and

-measure of hidden order $\mathrm{K}=\mathrm{D}_{1}-\mathrm{D}_{40}$ (for positive $\mathrm{q}$ )

Information entropy $D_{1}$ is a measure of the organization of the structure under study, $\mathrm{q}$ is the control parameter $\mathrm{q}=[-$ $40+40]$. With increasing parameter $\mathrm{K}=\mathrm{D}_{1}-\mathrm{D}_{40}$, the structure becomes more ordered, the system is pumped with information. The spectrum of information resonances $\Delta 40^{*}$ and structural dimensions $d^{*}$ characterizes the Meso levels of fractals forming the investigated multifractal. ${ }^{10,14}$

The moment of origin of a fractal corresponds to the indicator of its fractal dimension of boundaries $\mathrm{D}_{0}$, and its decay corresponds to the fractal dimension $\mathrm{D}_{-40}$, their ratio determines the assessment of the structural stability of the Meso-level (a measure of adaptability). ${ }^{12,13,14}$ The main indicators that determine the algorithm of self-organization of structures of dynamic systems include the measure of dynamic stability $\Delta_{i}$, which remains constant, and the indicator of periodic adaptive adjustment $m$ of the structure to external influences. Roots of the generalized Golden ratio $\Delta_{1}=0.618 ; \Delta_{2}=0.465$; $\Delta_{3}=0.380 ; \quad \Delta_{4}=0.324 ; \quad \Delta_{5}=0.285 ; \quad \Delta_{6}=0.255 ; \quad \Delta_{7}=0.232 ;$ $\Delta_{8}=0.213$ are the stability code of structures in different systems of living and inanimate nature. The transition to chaos occurs when the values of $\Delta_{\mathrm{i}}$ range from im $\Delta_{\text {imax }}=0,618$ to $\Delta_{\text {imin }}=0,213$ (Table 1).

Table 1: Information resonances $\Delta \mathrm{D}$, cell size d, and multifractal characteristics of structural boundaries of rat corneal tissue inhomogeneities after 10 and 20 days of exposure

\begin{tabular}{lllllllllll} 
index & days & $\begin{array}{l}\text { psycho } \\
\text { a type }\end{array}$ & $\Delta \mathbf{D}$ & $\begin{array}{c}\mathrm{d} \\
\text { pic }\end{array}$ & Do & $\mathrm{D}_{1}$ & $\mathrm{D}_{2}$ & $\mathrm{D}_{40}$ & $\mathrm{D}-40$ & D1-D40 \\
\hline 8.03.17.10 & 10 & sustain. & 1,723 & 50 & 0,800 & 0,665 & 0,631 & 0,557 & 2,279 & 0,108
\end{tabular}


Table 1: (Continued)

\begin{tabular}{|c|c|c|c|c|c|c|c|c|c|c|}
\hline index & days & $\begin{array}{l}\text { psycho } \\
\text { a type }\end{array}$ & $\Delta \mathrm{D}$ & $\begin{array}{c}\text { d } \\
\text { pic }\end{array}$ & Do & D1 & D2 & $D_{40}$ & $D-40$ & $D_{1}-D_{40}$ \\
\hline \multirow{2}{*}{$4.03 .17 \cdot 10$} & \multirow{2}{*}{10} & \multirow{2}{*}{ Non sustain. } & 1,574 & 45 & 0,831 & 0,625 & 0,589 & 0,522 & 2,096 & 0,103 \\
\hline & & & 1,566 & 50 & 0,813 & 0,612 & 0,570 & 0,493 & 2,059 & 0,119 \\
\hline \multirow{11}{*}{ 14ГЭ10 } & \multirow{11}{*}{20} & \multirow{11}{*}{ sustain. } & 0,566 & 10 & 0,686 & 0,663 & 0,655 & 0,641 & 1,206 & 0,022 \\
\hline & & & 0,781 & 16 & 0,666 & 0,631 & 0,620 & 0,595 & 1,376 & 0,036 \\
\hline & & & 0,846 & 18 & 0,661 & 0,621 & 0,609 & 0,578 & 1,423 & 0,044 \\
\hline & & & 0,940 & 21 & 0,652 & 0,611 & 0,595 & 0,559 & 1,499 & 0,053 \\
\hline & & & 0,999 & 23 & 0,641 & 0,596 & 0,581 & 0,543 & 1,542 & 0,047 \\
\hline & & & 1,018 & 28 & 0,628 & 0,575 & 0,553 & 0,509 & 1,527 & o,o66 \\
\hline & & & 1,211 & 31 & 0,633 & 0,573 & 0,551 & 0,503 & 1,714 & 0,07 \\
\hline & & & 1,322 & 36 & 0,621 & 0,555 & 0,533 & 0,484 & 1,805 & 0,071 \\
\hline & & & 1,462 & 42 & 0,617 & 0,545 & 0,525 & 0,477 & 1,939 & 0,067 \\
\hline & & & 1,535 & 46 & 0,625 & 0,564 & 0,548 & 0,470 & 2,004 & 0,095 \\
\hline & & & 1,621 & 49 & 0,582 & 0,510 & 0,491 & 0,440 & 2,061 & 0,070 \\
\hline \multirow{5}{*}{ 15ГЭ10 } & \multirow{5}{*}{20} & \multirow{5}{*}{ Non sustain. } & 1,214 & 31 & 0,694 & 0,623 & 0,602 & 0,549 & 1,763 & 0,074 \\
\hline & & & 1,374 & 38 & 0,711 & 0,623 & 0,602 & 0,548 & 1,922 & 0,075 \\
\hline & & & 1,465 & 41 & 0,698 & 0,604 & 0,573 & 0,494 & 1,958 & 0,111 \\
\hline & & & 1,529 & 45 & 0,701 & 0,598 & 0,576 & 0,517 & 2,046 & 0,081 \\
\hline & & & 1,708 & 50 & 0,671 & 0,569 & 0,542 & 0,449 & 2,157 & 0,120 \\
\hline ЗК1о & - & Ambivalent & 1,811 & 50 & 0,691 & 0,572 & 0,542 & 0,476 & 2,287 & o,o96 \\
\hline
\end{tabular}

The functional relation of the parameter of order $K_{\mathrm{s}}$ with the measure of adaptivity and dynamic stability is represented by extreme lines: the upper one (lines a and c) characterizes changes in the structure of the cornea of an animal with an unstable psychotype. for its energy and information levels, a positive change in entropy $(\Delta H>0)$ is noted during informa- tion transformations; the lower one (lines b and d) characterizes changes in the structure of the cornea of an animal with a stable psychotype for its energy and information levels, a negative change in entropy $(\Delta \mathrm{H} \leq 0)$ is noted during information transformations.

Table 2: Metaphysical levels of structural stability $D_{0} / D_{40}$ measure of stability $\left(\Delta_{i}\right)$, the limit of adaptation of the system $\left(A_{\mathrm{m}}{ }^{*}\right)$ to the restructuring of the structure of corneal tissues under conditions of similarity of the limit state

\begin{tabular}{|c|c|c|c|c|c|c|c|c|c|}
\hline index & $\begin{array}{l}\text { psycho } \\
\text { a type }\end{array}$ & $D_{0} / D_{-40}$ & $A_{\mathrm{m}}$ & $\Delta i$ & $\boldsymbol{A}_{\mathrm{m}}^{*}$ & $m$ & $m^{*}$ & $\Delta H$ & ВЭП(days) \\
\hline $8.03 \cdot 17 \cdot 10$ & sustain. & 0.351 & 0.324 & 0.324 & 0.87 & 1 & 8 & +0.011 & \\
\hline \multirow{2}{*}{$4.03 \cdot 17 \cdot 10$} & \multirow{2}{*}{ Non sustain. } & 0.397 & 0.380 & 0.380 & 0.79 & 1 & 4 & +0.001 & 10 \\
\hline & & 0.395 & 0.380 & 0.380 & 0.79 & 1 & 4 & +0.003 & \\
\hline \multirow[t]{7}{*}{ 14ГЭюо } & \multirow[t]{7}{*}{ sustain. } & 0.569 & 0.57 & 0.324 & 0.87 & 2 & 8 & -0.006 & 20 \\
\hline & & 0.484 & 0.48 & 0.232 & 0.98 & 2 & 64 & -0.006 & \\
\hline & & 0.465 & 0.46 & 0.213 & 0.99 & 2 & 128 & -0.003 & \\
\hline & & 0.435 & 0.46 & 0.213 & 0.99 & 2 & 128 & -0.007 & \\
\hline & & 0.416 & 0.380 & 0.380 & 0.79 & 1 & 4 & +0.001 & \\
\hline & & 0.411 & 0.380 & 0.380 & 0.79 & 1 & 4 & -0.002 & \\
\hline & & 0.370 & 0.380 & 0.380 & 0.79 & 1 & 4 & -0.001 & \\
\hline
\end{tabular}


Table 2: (Continued)

\begin{tabular}{|c|c|c|c|c|c|c|c|c|c|}
\hline index & $\begin{array}{l}\text { psycho } \\
\text { a type }\end{array}$ & $D_{0} / D_{-40}$ & $A_{\mathrm{m}}$ & $\Delta \mathbf{i}$ & $\boldsymbol{A}_{\mathrm{m}}^{*}$ & $m$ & $m^{*}$ & $\Delta H$ & ВЭП(days) \\
\hline \multirow{9}{*}{ 15ГЭ10 } & \multirow{9}{*}{ Non sustain. } & 0.344 & 0.324 & 0.324 & 0.87 & 1 & 8 & -0.022 & \\
\hline & & 0.318 & 0.324 & 0.324 & 0.87 & 1 & 8 & -0.002 & \\
\hline & & 0.312 & 0.285 & 0.285 & 0.92 & 1 & 16 & +0.011 & \\
\hline & & 0.282 & 0.285 & 0.285 & 0.92 & 1 & 16 & -0.035 & \\
\hline & & 0.394 & 0.380 & 0.380 & 0.79 & 1 & 4 & $+0,004$ & \\
\hline & & 0.370 & 0.380 & 0.380 & 0.79 & 1 & 4 & -0.009 & \\
\hline & & 0.356 & 0.380 & 0.380 & 0.79 & 1 & 4 & +0.009 & \\
\hline & & 0.343 & 0.324 & 0.324 & 0.87 & 1 & 8 & +0.002 & \\
\hline & & 0.311 & 0.324 & 0.324 & 0.87 & 1 & 8 & +0.028 & \\
\hline ЗК1O & Ambivalent & 0.306 & 0.324 & 0.324 & 0.87 & 1 & 8 & -0.089 & control \\
\hline
\end{tabular}

After 10 days of field exposure to a laboratory animal, regardless of its psychotype (upper lines), a positive change in entropy indicates the establishment of an equilibrium state of structural levels due to thermodynamic self-organization. The equilibrium state of the corneal structure is limited by the measure of adaptivity $A_{\mathrm{m}}=0.3 / 0.4$. After 20 days field exposure in the range of adaptability of $A_{\mathrm{m}}=0,3 / 0,4$ observed a single transition from the top line on the bottom and bottom on the top line that is expressed by the change of the order parameter $K_{\mathrm{s}}$ energy-information levels of the structure of the cornea (tab.1,2). In the range, $A_{\mathrm{m}}=0.4 / 0.57$ the energyinformational levels of the corneal structure of the laboratory animal correspond to the stable psychotype $(\Delta \mathrm{H} \leq 0)$. Information transforming the image of the tissue structure of the cornea allows setting the order parameter critical energy-in- formation level in the structure of the cornea, being the balance of entropy $\Delta \mathrm{H}=0: K_{\mathrm{s}}{ }^{0}=0,055$-critical parameter-level structures of the cornea of the animal with a stable psycho; $K_{\mathrm{s}}{ }^{0}=0,08$-critical parameter-level structures of the cornea of an animal with an unstable psycho.

The obtained estimates of the critical order parameters correspond to the stationary energy-information levels of the corneal structure States of laboratory animals, taking into account their psychotype, and can be used to determine the boundaries of the order parameter of the structural levels of the States of degradation(disease) $K_{\mathrm{s}}>K_{\mathrm{s}}{ }^{0}$ and self-organization (health) $K_{\mathrm{s}} \leq K_{\mathrm{s}}{ }^{0}$. Based on the validity of these provisions, the limits of changes in the multifractal parameters of the structure of corneal tissue images in laboratory animals were established (Table 3,4).

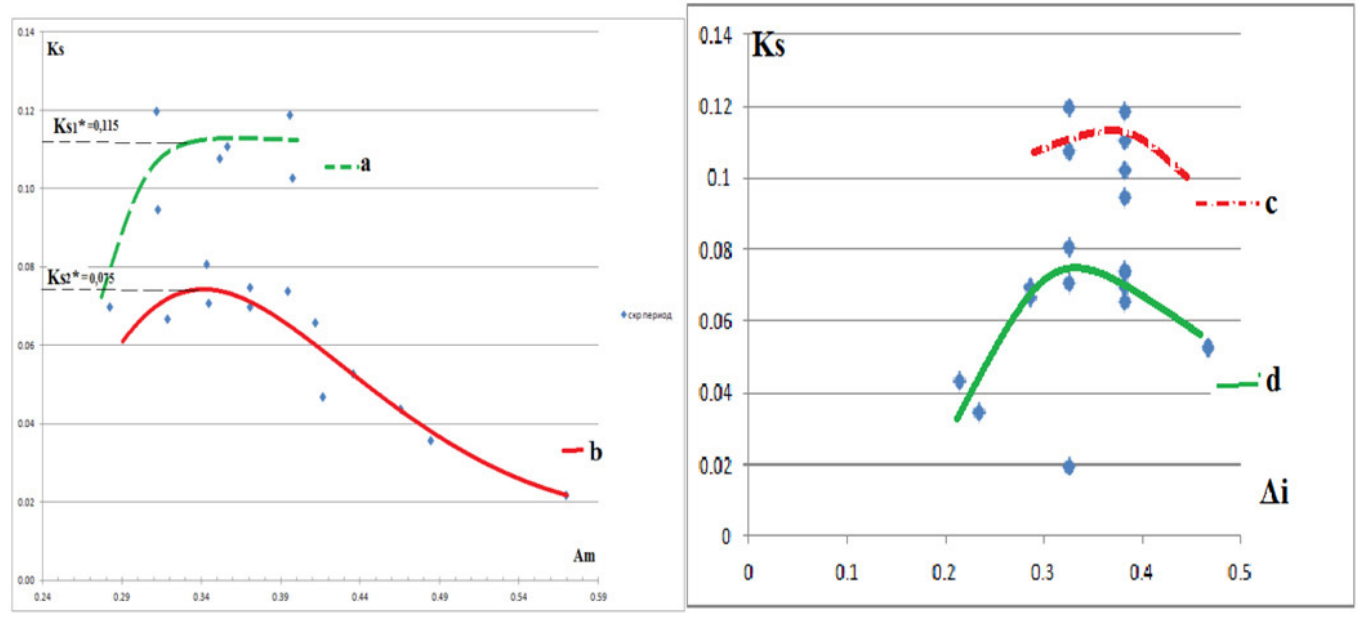

Figure 2: Dependence of the order parameter $K=D_{1}-D_{40}$ of the corneal tissue structure on the structural stability (adaptive capacity ) $\mathrm{A}_{\mathrm{m}}$ and stability $\Delta_{\mathrm{i}}$ : a) $K_{2 \max }=0,12, \mathrm{~A}_{\mathrm{m}}=0,4$ b) $K_{1 \max }=0,08, \mathrm{~A}_{\mathrm{m}}=0,35$; C) $K_{2 \max }=0,12, \Delta_{\mathrm{i}}=0,380 ;$ d) $K_{2 \max }=0,08, \Delta_{\mathrm{i}}=0,324$ 
Table 3: Multifractal parameters of energy-informational levels of structural adaptation of corneal tissues of laboratory animals with different psychotypes after 10 days of exposure to a rotating electric field

\begin{tabular}{lcc}
$\begin{array}{l}\text { Parameters } \\
\text { structures }\end{array}$ & $\begin{array}{c}\text { Laboratory animal psychotype } \\
\text { Stable } \\
\text { "disease" }\end{array}$ & $\begin{array}{c}\text { Unstable } \\
\text { "disease" }\end{array}$ \\
$\mathrm{K}_{\mathrm{s}}$ & 0,108 & $0,103 \div 0,119$ \\
$\mathrm{D}_{\mathrm{o}}$ & 0,8 & $0,813 \div 0,831$ \\
$\mathrm{D}_{1}$ & 0,665 & $0,612 \div 0,625$ \\
$\mathrm{D}_{2}$ & 0,631 & $0,57 \div 0,58$ \\
$\Delta \mathrm{D}$ & 1,723 & $1,566 \div 1,574$ \\
$\mathrm{D}_{\mathrm{o}} / \mathrm{D}_{-40}$ & 0,35 & 0,4 \\
$\Delta_{\mathrm{i}}$ & 0,324 & 0,38 \\
$\mathrm{~A}_{\mathrm{m}}{ }^{*}$ & 0,87 & 0,79 \\
$\mathrm{~d}, \mathrm{pxs}$ & 50 & $45 \div 50$ \\
\hline
\end{tabular}

Based on the results of stress adaptation of laboratory animals, we can assume that the boundaries of the "norm of randomness" of information entropy $\mathrm{D}_{1}$ of the "health" state coincide, regardless of the psychotype. Information entropy $\mathrm{D}_{1}$ in "disease" is higher in an animal with an unstable psychotype. The obtained results showed that the synergy effects are manifested near the points of non-equilibrium phase transition, which provides self-optimization of the structure under stress. Application of the fractal approach and synergetics to the study of the structure of biological objects makes it possible to increase the information content of experimental research results.

Table 4: Multifractal parameters of energy and information levels of structural adaptation of corneal tissues of laboratory animals with different psychotypes after 20 days of exposure to a rotating electric field

\begin{tabular}{|c|c|c|c|c|c|c|c|c|c|c|c|}
\hline \multirow{3}{*}{$\begin{array}{l}\text { Parameters } \\
\text { structures }\end{array}$} & \multicolumn{11}{|c|}{ Laboratory animal psychotype } \\
\hline & \multicolumn{7}{|c|}{ Stable } & \multicolumn{4}{|c|}{ Unstable } \\
\hline & \multicolumn{4}{|c|}{ "Health" } & \multicolumn{3}{|c|}{ "disease" } & \multicolumn{2}{|c|}{ "Health" } & \multicolumn{2}{|c|}{ "disease" } \\
\hline $\mathrm{K}_{\mathrm{s}}$ & \multicolumn{4}{|c|}{$0,002 \div 0,055$} & \multicolumn{3}{|c|}{$0,055 \div 0,095$} & \multicolumn{2}{|c|}{$0,073 \div 0,08$} & \multicolumn{2}{|c|}{$0,08 \div 0,12$} \\
\hline $\mathrm{D}_{\mathrm{o}}$ & \multicolumn{4}{|c|}{$0,641 \div 0,686$} & \multicolumn{3}{|c|}{$0,582 \div 0,628$} & \multicolumn{2}{|c|}{$0,694 \div 0,711$} & \multicolumn{2}{|c|}{$0,671 \div 0,698$} \\
\hline $\mathrm{D}_{1}$ & \multicolumn{4}{|c|}{$0,596 \div 0,663$} & \multicolumn{3}{|c|}{$0,51 \div 0,575$} & \multicolumn{2}{|c|}{$0,598 \div 0,623$} & \multicolumn{2}{|c|}{$0,569 \div 0,604$} \\
\hline $\mathrm{D}_{2}$ & \multicolumn{4}{|c|}{$0,581 \div 0,655$} & \multicolumn{3}{|c|}{$0,491 \div 0,553$} & \multicolumn{2}{|c|}{$0,576 \div 0,602$} & \multicolumn{2}{|c|}{$0,542 \div 0,573$} \\
\hline$\Delta \mathrm{D}$ & \multicolumn{4}{|c|}{$0,566 \div 1,0$} & \multicolumn{3}{|c|}{$1,018 \div 1,621$} & \multicolumn{2}{|c|}{$1,214 \div 1,529$} & \multicolumn{2}{|c|}{$1,465 \div 1,708$} \\
\hline $\mathrm{D}_{0} / \mathrm{D}_{-40}$ & \multicolumn{4}{|c|}{$0,416 \div 0,57$} & \multicolumn{3}{|c|}{$0,282 \div 0,411$} & \multicolumn{2}{|c|}{$0,343 \div 0,394$} & \multicolumn{2}{|c|}{$0,311 \div 0,356$} \\
\hline$\Delta_{\mathrm{i}}$ & 0,213 & 0,232 & 0,324 & 0,38 & 0,285 & 0,324 & 0,38 & 0,324 & 0,38 & 0,324 & 0,38 \\
\hline$A_{m}{ }^{*}$ & 0,99 & 0,98 & 0,87 & 0,79 & 0,92 & 0,87 & 0,79 & 0,87 & 0,79 & 0,87 & 0,79 \\
\hline d, pxs & \multicolumn{4}{|c|}{$10 \div 23$} & \multicolumn{3}{|c|}{$28 \div 49$} & \multicolumn{2}{|c|}{$31 \div 45$} & \multicolumn{2}{|c|}{$41 \div 50$} \\
\hline
\end{tabular}

\section{CONCLUSIONS}

Based on the developed mathematical model "information system of corneal tissue structure", multifractal image parameters were determined that allow us to quantitatively describe the adaptive capacity of the corneal tissue structure caused by a stress reaction to the external influence of an experimental animal. In an animal with a stable psychotype, the fractal dimension of the boundaries $D_{0}$ is smaller, and the fractal dimensions $D_{1}, D_{2}, D_{40}$ are higher compared to an animal with an unstable psychotype, i.e. information systems differ in the degree of randomness. After 20 days of field exposure, a new spectrum of Meso levels and dynamic stability appears in the information system of the structure of corneal tissues. At the same time, in an animal with a stable Psychotype, non-equilibrium Meso-levels with dynamic self-organization prevail (the entropy of the levels decreases $\Delta \mathrm{H} \leq 0$ ).

\section{REFERENCES}

1. Kulikov AN, Kudryashova EV, Gavrilyuk VN, Maltsev DS. Indicators of corneal tissue volume in normal conditions and keratoconus. Modern technologies in ophthalmology. Sci Pract J 2019; 5 (30):292.

2. Abovyan AA, Zilfyan AA. The role of matrix metalloproteinase- 9 in the diagnosis of keratoconus. Mod Tech Ophth Soci 2018; 5: 263-265.

3. Vstovsky GV, Kolmakov AG, Bunin I. Zh. Introduction to the multi-fractal parameterization of structures of materials, Izhevsk: "Regular and chaotic dynamics", 2001:115

4. Ivanova VS. The universality of self-organization of dynamic structures of living and bone nature. Synerget 1999;2:85-38.

5. Prangishvili VI, Trapeznikov VA. Entropy and other systemic laws: Questions of management of complex systems. Inst Control Problems Sci 2003:428.

6. Minina EN. Fainzilberg LS. et al. Analysis of cardio hemodynamic functioning using the entropy approach and the phase plane method. Complexity Mind Post-Nonclassics 2016; 4:5-17.

7. Saraev IA, Dovgan IA. New diagnostic possibilities based on the analysis of nonlinear properties of homeostasis. Kursk Scientific and Practical Bulletin "Man and his health". 2005; 2:64-74.

8. Adaykin VI, Braginsky MY, Eskov VM, Rusak SN, Khadartsev AA, Filatova OE. A new method for identifying chaotic and stochastic parameters of the ecological environment. Bull New Med Techn. 2006;2:39-41.

9. Khadartsev AA. Theoretical foundations of new medical technologies. Bull Int Acad Sci 2006;1:22-28. 
10. Laptev DS, Egorkina SB, Stepanov VA, Belykh VV. Study of structural changes in corneal tissues of experimental animals in a rotating electric field by the method of fractal parameterization. Intelligent systems in production. 2019;17; 4:32-40.

11. Zainaeva TP, Egorkina SB. Influence of a rotating electric field on the "mother - placenta - fetus" system in rats with different predictive stress resistance. Human Ecology 2016;8:3-7.

12. Ivannikov VP, Sufiyanov VG, Belykh VV, Stepanov VA. Fractal analysis of X-ray diffraction patterns. Bull ISTU Kalashnikov 2009;3:150-154.

13. Stepanov VA, Belykh VV. A program for comparative fractal analysis of raster images. Certificate of state registration of the computer program No. 2016615852. State date Registration in the Register of computer programs 2016:222.

14. Puchkov GG, Perelman LS. Zadorozhnaya MN. Electric fields of EHV transmission and their modelling. Ultrahigh voltage electrical transmission and ecology: Collection of scientific works of ENIN.. 1986: 140-154.

15. Patent 166292 Russian Federation. A device for studying the effect of a rotating electric field on biological objects / Egorkina S.B., applicant and patent holder, SBEE HPE Izhevsk State Medical Academy. No. 2016:10.02.93.

16. Klimontovich YL. Introduction to physics of open systems. Yanus-K, 2002:284. 